\title{
PENGARUH LATIHAN FOOTWORK TERHADAP PUKULAN DROPSHOT DALAM PERMAINAN BULUTANGKIS
}

\author{
Muhammad Salahuddin
}

Universitas Muhammadiyah Luwuk Banggai

Email: muhammmadsalahuddin252@gmail.com

Orcid Id: https://orcid.org/0000-0001-7963-8688

$\begin{array}{ll}\text { Article received } & : 2021-06-23 \\ \text { Review process } & : 2021-06-27 \\ \text { Article published } & : 2021-06-29\end{array}$

\begin{abstract}
This study focuses on the problem of PJKR Students at Unismuh of Luwuk Banggai when participating in a badminton championship. Their average performance shows that they rarely gave dropshots during the match. In fact, they almost never did this because of the lack of training given that they are doubtful to shoot. The purpose of this study was to determine the effect of footwork training on dropshots during badminton matchesq for PJKR Unismuh Luwuk students and the research method used for this study was one pretest-posttest group. Based on the results of the data analysis of the drop shot skills in badminton game with a different test (paired t-test) between the initial test and the final test in the experimental group of footwork exercises, the $t$-count $=12.310$ ( $\alpha$ $0.05>$ sig $=0.000$ ) with the mean score of the initial test was 30.75 and the final test result was 38.83. Thus, there is an increase of 8.08 point. This one indicates a significant effect of footwork training on drop shot skills in badminton. The results of the data analysis of the accuracy of the drop shot in the badminton game with a different test (paired t-test) between the initial test and the final test in the control group obtained t count $=1.567(670.05<$ sig $=0.145)$ while in the control group shows the score at 0.17 and the final test result is 30.92, thus there is an increase of 0.75. Thus, it can be stated that the experimental group has footwork exercises and has a significant effect on improving drop shot skills in badminton games for PJKR Unismuh Luwuk Banggai students.
\end{abstract}

Keywords: Footwork Exercise, Dropshot, Badminton

\begin{abstract}
Abstrak
Penelitian ini berfokus pada permasalahan Mahasiswa PJKR Unismuh Luwuk Banggai pada saat mengikuti kejuaran badminton, rata-rata dalam permainan kurang sekali dalam menerapkan pukulan dropshot, bahkan hampir tidak pernah melakukan hal ini karena kuragnya latihan yang diberikan sehingga keraguan dalam melakukan pukulan. Tujuan penelitian ini untuk mengetahui pengaruh pada latihan footwork terhadap pukulan dropshot dari permainan bulutangkis pada mahasiswa PJKR Unismuh Luwuk dan metode penelitian yang digunakan untuk penelitian ini ialah one pretest-posttest group. Berdasarkan hasil analisis data keterampilan pukulan dropshot dalam permainan bulutangkis dengan uji beda (uji-t berpasangan) antara tes awal dan tes akhir pada kelompok eksperimen latihan footwork diperoleh nilai $t$ hitung $=12.310(\alpha 0.05>$ sig $=0.000)$ dengan rata-rata (Mean) tes awal 30.75 dan hasil tes akhir 38.83, dengan demikian terjadi peningkatan sebesar 8.08. Dengan demikian bahwa ada pengaruh yang signifikan latihan footwork terhadap keterampilan pukulan dropshot dalam permainan bulutangkis. hasil analisis data ketepatan pukulan dropshot dalam permainan bulutangkis dengan uji beda (uji-t berpasangan) antara tes awal dan tes akhir pada kelompok kontrol diperoleh nilai thitung $=1.567(\alpha 0.05<$ sig $=0.145$ ) sedangkan pada kelompok kontrol rata-rata (Mean) tes awal 30.17 dan hasil tes akhir 30.92, dengan demikian terjadi peningkatan sebesar 0.75. Dengan demikian dapat dikemukakan bahwa kelompok eksperimen latihan footwork dan memberikan pengaruh yang signifikan terhadap peningkatan keterampilan pukulan dropshot dalam permainan bulutangkis pada mahasiswa PJKR Unismuh Luwuk Banggai.
\end{abstract}

Kata Kunci: Latihan Footwork, dropshot, Bulutangkis 


\section{Pendahuluan}

Bulutangkis ialah bagian pada cabang gerakan jasmani di mana sebagai olahraga sangat populer berada di Indonesia. Gerakan jasmani yang dikenal sebagai olah raga yang satu ini sangat diminati kelompok umur yang berbeda-beda, peringkat kecakapan, pemain laki-laki dan pemain perempuan melakukan badminton biasanya mereka melakukannya di dalam suatu ruangan dan dapat dilakukan juga di luar ruangan untuk suatu hal dalam persaingan atau pertandingan dan dimanfaatkan sebagai rekreasi. Dalam permainan bulutangkis ini bertujuan untuk menahan bola agar dapat mempertahankan posisi shuttlecock bisa tidak berada jatuh didalam lapangan diri sendiri dan memberikan upaya berusaha sehingga shuttlecock tepat jatuh di area bidang lapangan lawan permainan.

Pada Mahasiswa PJKR Unismuh Luwuk Banggai dalam mengikuti lomba badminton yang dibuat dilingkungan kampus, maupun dluar yang menjadi salah satu pokok permasalahan adalah pukulan dropshot dibandingkan dengan teknik dasar yang lainnya. Pukulan dropshot ini merupakan sebuah pukulan yang susah dijangkau oleh lawan karena penempatan bola berada pada bagian muka net sehingga kosentrasi pergerakan lawan terganggu. Dalam pelaksanaan dropshot biasanya digunakan gerakan langkah footwork. Menurut Muhajir (2004:68) teknik gerakan kaki (footwork) adalah salah satunya. Langkah berurutan, baik untuk langkah kedepan, kesamping ataupun kebelakang kaki pada posisi kanan dan kaki posisi kiri yang bergerak secara berurutan maupun secara berdampingan, dengan langkah secara bergantian maupun bersilangan

Menurut Ardiansyah Nur (2020:2) Salah satu faktor yang perlu diperhatikan dalam rangka meningkatkan kemampuan dan prestasi atlit adalah penerapan prinsip-prinsip latihan dalam pelaksanaan program latihan. Sehingga dalam penelitian ini menggunakan latihan footwork agar bisa membantu memecahkan persoalan yang ada dalam permainan bulutangkis khususnya pada mahasiswa PJKR. Rumusan masalah dalam penelitian ini adalah pengaruh latihan footwork terhadap pukulan dropshot mahasiswa PJKR Unismuh Luwuk dan Tujuan penelitian untuk mengetahui pengaruh latihan footwork terhadap pukulan dropshot mahasiswa PJKR Unismuh Luwuk.

Herman Subarjah (2000:13) permainan bulutangkis ini sifatnya individu yang mana perlawanan satu pemain akan melawan pada satu pemain lainnya, juga pemain untuk yang dua pemain akan melawan pada dua pemain lainnya semua itu dinamakan permainan bulutangkis. Dalam permainan bulutangkis ada beberapa hal mpenting byang kita ketahui seprti pukulan dropshot. Tanjung (2005:32) yang mengatakan bahwa dropshot adalah memukul bola bulutangkis dengan melakukannya seperti smash, memiliki beda di posisi raketnya ketika melakukan dengan shuttlecock. Berkenaan dengan memukul dengan teknik dropshoot, menurut Syahri Alhusin (2007:46-47) juga memaparkan: Dropshoot itu dinamakan pukulan potong yang mana caranya pukulan seperti smash. Bedanya untuk meletakkan berkenaan dengan teknik shuttlecock raket memiliki posisi yang berbeda. Memukul, mendorong dan menyentuh Shuttlecock secara lembut.

Menurut Sukadiyanto, (2005:5) segala kegiatan yang bertujuan mengembangkan untuk mengasah kemahiran cabang olahraga dengan cara meningkatkan inovasi media yang digunakan selaras dengan arah yang dimaksud juga buat kepentingan pada bulutangkis di bidang olahraga tersebut. Meraih prestasi yang sangat optimal, setiap atlet bulutangkis sangat penting proses latihan yang dilakukan karena menuju tujuan fundamental dari latihan ialah menaikkan fungsi dari atlet itu sendiri juga dapat mengembangkan kemahiran biomotor pada tahap nilai yang paling tinggi (Awan Hariono, 2006:6). Latihan pada permainan ini adalah bagaimana proses berlatih dilakukan dengan cara sistematis dan berulangulangdengan pemberian beban secara progresif yang disampaikan oleh Awan Hariono (2006: 1). 
Djoko Pekik Irianto (2002:11-12) menjelaskan suatu bentuk pelatihan ialah suatu perbaikan latihan gerak yang menjadi efisien dengan dilakukan berulang-ulang dan melakukan latihan dengan cara teratur, memiliki perencanaan, dapat mengaplikasikan pola dan sistem yang ditentukan, memiliki metode yang dilakukan berterusan seperti pada gerakan yang pertama sangat susah dilakukan gerakan tidak terorganisasi menjadi otomatis dan mudah dilakukan.

Melakukan gerakan yang efektif pada pemain yang bermain bulutangkis posisi kedua kaki fungsinya untuk menyangga pada tubuh agar dapat bergerak menuju penjuru arah secara sangat cepat, agar bisa tubuh diberi posisi yang diinginkan. Banyak gerakan pada kaki atau langkah kedua kaki untuk bermain permainan bulutangkis selalu disebutkan dengan istilah footwork. Herman Subardjah (2000:27) menjelaskan footwork yaitu banyak gerakan pada langkah dua kaki dapat mengendalikan badan seseorang untuk memiliki posisi badan yang baik agar mudah dalam gerak saat melakukan pukulan shuttlecock mengikut posisinya. Sapta Kunta (2010:26) yaitu bermacam prinsip pada dasar footwork untuk bermain bulutangkis yaitu posisi pada kaki yang benar dengan cara kedua tangan berguna untuk memegang alat raket ketika bola dipukul akan berakhir sesuai pada arah tangan mengayun.

Pada permainan yang sangat cepat dan shuttlecock diusahakan agar tidak jatuh didaerah dilapangan sendiri, menjadikan usaha pemain menjadi kuat sehingga pemain menggerakkan badanya keseluruh arah secara tangkas merupakan peranan penting dalam permainan bulutangkis, dengan latihan yang diberikan dengan harapan bisa membawa perubahan dalam permainan bulutangkis sehingga mahasiswa PJKR nantinya akan lebih mampu dalam melakukan pukulan dropshot.

Dengan demikian latihan footwork mempuyai peranan penting dalam permainan bulutangkis, dimana latihan ini bisa memberikan perubahan yang cukup signifikan karena dari pergerakan langkah kaki dan penempatan posisi shuttlecock yang baik dan benar. Sehingga latihan footwork mampu memperlihakan kemampuan pukulan dropshot.

\section{Metode}

Metode penelitian yang digunakan dalam ini bersifat eksperimen. Pandangan Ali Maksum (2012:65) untuk mengetahui sebab dan akibat diantara variabelnya maka penelitian dilakukan secara teliti karena penelitiannya yang bersifat eksperimen. Penelitian eksperimen ini masuk kedalam kategori eksperimen bersifat semu, yaitu terdapat sampel yang dikontrol sepenuhnya atau ditempatkan oleh peneliti. Desain yang digunakan untuk penelitian ini ialah one pretest-posttest group seperti gambar dibawah ini:

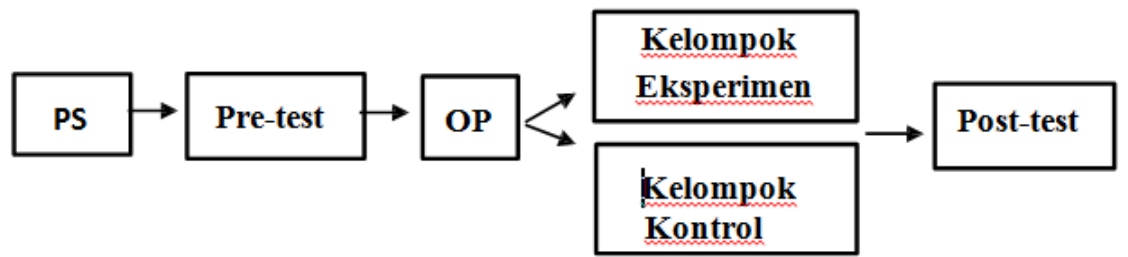

\section{Gambar 1: Desain Penelitian}

Keterangan:

PS : Populasi dan Sampel

Pre-test : Test awal dengan digunakannya tes pukulan dropshoot

OP : Ordinal Pairing (membagikan Kelompok)

Post-test : Test akhir dengan digunakannya tes pukulan dropshoot

Gambaran konsep desain untuk penelitian yang menggunakan pre-test dan posttest. Terdapat pengaruh pada dua variabel yang dapat terlibat sebagai berikut: 
Journal PANRITA: Journal of Education, Research and Technology

Homepage: https://journal.umpalopo.ac.id/index.php/panrita

Email: mailto:panrita.fkipumpalopo@gmail.com

\section{Tabel 1: Rancangan Penelitian}

\begin{tabular}{|c|c|c|c|}
\hline Kelompok & $\begin{array}{c}\text { Tes Awal } \\
\text { (Pre-Test) }\end{array}$ & Treatment & $\begin{array}{c}\text { Tes Akhir } \\
\text { (Post-test) }\end{array}$ \\
\hline Eksperimen & Drop Shot & $\begin{array}{c}\text { Latihan Footwork } \\
\text { Media }\end{array}$ & Drop shot \\
\hline Kontrol & Drop Shot & - & Drop shot \\
\hline
\end{tabular}

Penelitian dilakukan di Kampus Unismuh Luwuk Banggai yang dilaksanakan pada bulan September sampai November 2020 dan yang menjadi populasinya adalah mahasiswa PJKR yang semester 5 yang berjumlah 24 orang. Menurut Arikunto (2004:118) bahwa menentukan besarnya sampel yang akan diteliti, jika jumlah nya kurang dari 100 sampel maka lebih baik diambil semua, jadi sampel penelitian berjumlah 24 orang terdiri dari putra. Penelitian ini dilakukan untuk melatih kemampuan mahasiswa PJKR khususnya dalam melakukan pukulan dropshot. Sugiyono (2010: 61) menjelaskan bahwa variable penelitian adalah suatu petunjuk atau sifat atau tanda dari orang, objek atau kegiatan yang mempunyai variasi tertentu yang ditetapkan oleh peneliti untuk dipelajari lalu ditarik kesimpulannya

Menurut Arikunto S. (2010:192), mengemukakan bahwa metode pengumpulan data yang tepat adalah dengan cara-cara yang dapat digunakan oleh peneliti untuk pengumpulan data. Teknik pengumpulan data dilakukan melalui tes dan pengukuran. Melalui tes dan pengukuran ini maka kita akan mendapatkan data yang objektif. Tes adalah alat ukur yang bisa dipakai untuk mendapatkan data yang objektif. Korelasi adalah hubungan antara variabel yang satu dengan variabel yang lain menurut Surisman (2010: 52).

Instrument tes yang digunakan adalah latihan footwork menggunakan media. Proses latihan selama 12 kali pertemuan sudah dapat dikatakan terlatih, karena sudah ada perubahan yang menetap pada responden, sementara penelitian ini dilaksanakan selama 14 kali termasuk tes awal dan tes akhir, pertemuan sehingga dianggap sudah dapat mendapatkan data yang baik dan tepat. Latihan Footwork yang diberikan sebagai berikut : 1) Gerakan yang dilakukan berulang-ulang mulai dari posisi tengah lapangan, melangkah ke pojok kanan depan, lalu kembali ke tengah dilanjutkan ke kiri depan dan kembali ke tengah. 2) Gerakan yang dilakukan berulang-ulang mulai dari posisi tengah melangkah ke arah samping ke kanan, kembali ke tengah lalu ke samping kanan dan kembali ke tengah. 3) Gerakan yang dilakukan berulang-ulang mulai dari posisi tengah melangkah mundur ke kanan belakang lalu kembali ke tengah dan melangkah mundur ke kiri belakang dan kembali ke tengah. Selanjutnya instrumen tes pukulan dropshot adalah Responden untuk uji tes berdiri pada tanda $\mathrm{X}$ berhadapan dengan pendamping tes yang berdiri di tengah-tengah lapangan yang bertarget pada tanda $\mathrm{Y}$ sambil memegang shuttle untuk memberi serve. Setelah pendamping tes memberikan serve, peserta tes boleh meninggalkan tempatnya dan melakukan pukulan dropshot dengan mendorong shuttle secara perlahan ke seberang jaring melewati atas net dan berusaha agar bola jatuh pada bidang sasaran yang bernilai tinggi. Bola yang dipukul peserta tes dihitung sebagai percobaan yang dilakukan 12 kali. Bola yang dipukul dengan benar dan memenuhi syarat-syarat tes serta jatuh di bidang sasaran, diberi nilai dari luar ke dalam 1, 2, 3, 4, 5. Bola yang bersarang pada net, keluar lapangan tidak diberi nilai. Bola yang jatuh tepat di atas garis sasaran dianggap masuk ke daerah sasaran yang bernilai tinggi. Penilaian : kuantitas nilai atau angka pada sasaran yang berhasil diperoleh 12 kali pukulan bola dengan sempurna, dicatat sebagai hasil akhir Peserta tes. 


\section{Hasil dan Pembahasan}

Data hasil tes keterampilan pukulan dropshot dalam permainan bulutangkis yang diperoleh dalam penelitian melalui kedua kelompok, yaitu kelompok latihan footwork (eksperimen) dan kelompok kontrol yang akan dianalisa dengan analisa deskriptif maupun analisa inferesial dalam kaitannya dengan teori yang mendasari penelitian ini agar mendapatkan interpretasi dari hasil analisis data.

\section{Hasil Deskriptif Pukulan Dropshot}

Hasil analisis deskriptif (gambaran umum) data penelitian yang terdiri dari nilai tes awal keterampilan pukulan dropshot dalam permainan bulutangkis pada kelompok yang mendapat perlakuan latihan footwork (A) dan kelompok kontrol (B) dapat dilihat dalam rangkuman hasil analisis deskriptif yang tercantum dibawah ini sehingga pada tabel ini bisa dijelaskan tentang gambaran keseluruhan tes awal dan tes akhir

Tabel 2: Rangkuman Deskripsi Data Tes Awal dan Tes Akhir Keterampilan Pukulan Dropshot dalam Permainan Bulutangkis Pada Kelompok Latihan footwork (A) dan Kelompok Kontrol

\begin{tabular}{lcccc}
\hline \multirow{2}{*}{ Statistik } & \multicolumn{2}{c}{ Kelompok Eksperimen } & \multicolumn{2}{c}{ Kelompok Kontrol } \\
\cline { 2 - 5 } & $\begin{array}{c}\text { Tes Awal } \\
\text { (A1) }\end{array}$ & $\begin{array}{c}\text { Tes Akhir } \\
(\mathbf{A 2})\end{array}$ & $\begin{array}{c}\text { Tes Awal } \\
(\text { B1) }\end{array}$ & $\begin{array}{c}\text { Tes } \\
\text { Akhir } \\
(\text { B2) }\end{array}$ \\
\hline $\mathrm{N}$ & 12 & 12 & 12 & 12 \\
\hline Mean & 30.75 & 38.83 & 30.17 & 30.92 \\
\hline Std. Deviation & 1.765 & 1,749 & 1.749 & 1.730 \\
\hline Range & 6 & 6 & 6 & 6 \\
\hline Minimum & 28 & 36 & 27 & 29 \\
\hline Maximum & 34 & 42 & 33 & 35 \\
\hline
\end{tabular}

\section{Uji Normalitas Data}

Sebelum dilakukan analisis data perlu diuji distribusi normalitas. Uji normalitas data dalam penelitian ini digunakan model Kolmogorov Smirnov. Hasil uji normalitas data yang dilakukan pada tes awal setiap kelompok dapat dilihat pada tabel di bawah ini.

Tabel 3: Rangkuman Uji Normalitas Data Tes Awal dan Tes Akhir Keterampilan Pukulan Dropshot dalam Permainan Bulutangkis dari setiap kelompok

\begin{tabular}{cccc}
\hline & \multicolumn{2}{c}{ Tests of Normality Shapiro-Wilk } \\
\cline { 2 - 4 } & Statistic & df & Sig. \\
\hline $\begin{array}{c}\text { Tes awal kelompok } \\
\text { eksperimen latihan footwork }\end{array}$ & 0.968 & 12 & 0.893 \\
\hline Tes awal kelompok kontrol & 0.975 & 12 & 0.954 \\
\hline $\begin{array}{c}\text { Tes akhir kelompok } \\
\text { eksperimen latihan footwork }\end{array}$ & 0.975 & 12 & 0.954 \\
\hline Tes akhir kelompok kontrol & 0.885 & 12 & 0.100 \\
\hline
\end{tabular}

\section{Uji T}

Berdasarkan hasil uji-t berpasangan yang dilakukan pada data hasil tes awal dan tes akhir keterampilan pukulan drop shoot dalam permainan bulutangkis pada masingmasing kelompok dapat dilihat pada 
Journal PANRITA: Journal of Education, Research and Technology

Homepage: https://journal.umpalopo.ac.id/index.php/panrita

Email: mailto:panrita.fkipumpalopo@gmail.com

Tabel 4: Rangkuman Hasil Uji-t Berpasangan Dari Setiap Kelompok

\begin{tabular}{clcccccc}
\hline Kelompok & Variabel & Mean & t-hit & df & A & sig & Ket \\
\hline Eksperimen & $\begin{array}{l}\text { Tes awal- } \\
\text { tes akhir }\end{array}$ & 8.083 & 12.310 & 11 & 0.05 & 0.000 & Signifikan \\
\hline Kontrol & $\begin{array}{l}\text { Tes awal- } \\
\text { tes akhir }\end{array}$ & 0.750 & 1.567 & 11 & 0.05 & 0.145 & $\begin{array}{c}\text { Tidak } \\
\text { Signifikan }\end{array}$ \\
\hline
\end{tabular}

\section{Terdapat Pengaruh yang Signifikan Kelompok Latihan Footwork Terhadap} Keterampilan Pukulan Dropshot dalam Permainan Bulutangkis.

Berdasarkan hasil analisis uji-t berpasangan menunjukkan bahwa kelompok latihan footwork mempunyai pengaruh yang signifikan terhadap keterampilan pukulan dropshot dalam permainan bulutangkis, yaitu thitung $=12.310(\mathrm{sig}=0.000<\alpha 0.05)$. Angka ratarata (Mean) tes awal 30.75 dan hasil tes akhir 38.83, dengan demikian terjadi peningkatan sebesar 8.08. mahasiswa PJKR setelah dilakukan latihan footwork mengalami perubahan pada sampel setelah melaksanakan perlakuan latihan footwork mengalami peningkatan pada pukulan dropshot. Menurut Suharno (1993:5) menjelaskan bahwa latihan ialah suatu proses penyempurnaan kualitas atlet secara sadar untuk mencapai prestasi yang maksimal yang diberi beban fisik dan mental secara teratur, terarah, bertahap, meningkat dan berulang-ulang waktunya. Footwork atau langkah kaki yang baik sangat berperan penting dalam kesuksesan permainan bulutangkis karena dalam melakukan footwork dengan baik dapat lebih mudah menjangkau sudut-sudut lapangan baik diarea depan net, di area samping lapangan maupun di area belakang lapangan. Menurut Alhusin (2007:30) bahwa untuk bisa memukul shuttlecock dengan baik, seorang atlet harus memiliki kecepatan gerak (kelincahan). Sehingga dapat disimpulkan bahwa latihan footwork dapat digunakan untuk melatih mahasiswa sehingga bisa meningkatkan pukulan dropshot dalam permainan bulutangkis.

\section{Tidak Terdapat Pengaruh yang Signifikan Kelompok Kontrol Terhadap} Keterampilan Pukulan Dropshot dalam Permainan Bulutangkis.

Berdasarkan hasil analisis uji-t berpasangan menunjukkan bahwa kelompok kontrol tidak mempunyai pengaruh yang signifikan terhadap keterampilan pukulan dropshot dalam permainan bulutangkis, yaitu thitung $=1.567(\mathrm{sig}=0.145>\alpha 0.05)$. Angka rata-rata (Mean) tes awal 30.17 dan hasil tes akhir 30.92, dengan demikian terjadi peningkatan sebesar 0.75 . Tanjung (2005: 32) yang mengatakan bahwa dropshot adalah memukul bola bulutangkis dengan melakukannya seperti smash, memiliki beda di posisi raketnya ketika melakukan dengan shuttlecock. Dalam hal ini, kelompok kontrol yang dimaksud tidak diberi perlakukan latihan footwork sama sekali. Kelompok ini hanya menjadi kelompok pembanding bagi kelompok eksperimen. Karena tidak adanya perlakuan dalam kelompok kontrol ini, peningkatan keterampilan pukulan dropshot dalam permainan bulutangkis mengalami perlambatan.

\section{Perbedaan Pengaruh yang Signifikan Kelompok Latihan Footwork Dan Kelompok Kontrol Terhadap Keterampilan Pukulan Dropshot dalam Permainan Bulutangkis.}

Berdasarkan hasil analisis varians (Uji F) diperoleh hasil $=124.249(\mathrm{sig}=0.000<\alpha$ 0.05). Hasil menunjukkan bahwa terdapat perbedaan dari kedua kelompok eksperimen dan kelompok kontrol. Perbedaan antara kelompok eksperimen dan kelompok kontrol terdapat perbedaan dimana kelompok eksperimen dari tes awal dan tes akhir mengalami peningkatan sebesar 8.08 dapat dikatakan memberikan pengaruh kepada mahasiswa PJKR dalam permainan bulutangkis, sedangkan kelompok kontrol hanya mengalami peningktan 0.75 
maka dapat dikatakan tidak memberikan pengaruh dalam permainan bulutangkis khusunya mahasiswa PJKR semester 5 tahun 2020.

Alhusin (2007:30 footwork adalah gerak kaki untuk mendekatkan diri pada posisi jatuhnya shuttlecock. Gerakan footwork merupakan gerakan kaki untuk menempatkan posisi badan sedemikian rupa untuk menghadapi shuttlecock, sehingga dapat melakukan pukulan dengan baik dan tetap dalam keadaan seimbang. Dalam permainan bulutangkis gerakan kaki juga mempunyai peranan penting, karena permainan ini adalah permainan yang cepat dan mengusahakan shuttlecock tidak jatuh di daerah permainan sendiri, sehingga setiap pemain berusaha bergerak ke segala arah dengan cepat dan seimbang.

Menurut Sukadiyanto, (2005: 5) segala kegiatan yang bertujuan mengembangkan untuk mengasah kemahiran cabang olahraga dengan cara meningkatkan inovasi media yang digunakan selaras dengan arah yang dimaksud juga buat kepentingan pada bulutangkis. Dengan adanya latihan yang dilakukan sehingga bisa mendapatkan hasil yang lebih baik pula, semakin bagus langkah footwork seorang pemain, maka akan dengan mudahnya untuk melakukan langkah dalam pukulan dropshot. Dengan demikian dalam permainan bulutangkis harus dibarengi dengan sebuah latihan kalau ingin mendapatkan sebuah perubahan dalam peningkatan prestasi. Prestasi tidak bisa didapatkan hanya begitu saja secara alami khusunya dalam permainan bulutangkis.

\section{Simpulan}

Data tes awal pada kelompok latihan footwork dengan jumlah sampel 12 orang memiliki nilai rata-rata 30.75, standart deviasi 1.765 . Nilai minimum 28 dan nilai maksimum 34 dengan range 6. Sedangkan data tes akhir dengan jumlah sampel 12 orang memiliki nilai rata-rata 38.83, standart deviasi 1.749 . Nilai minimum 36 dan nilai maksimum 42 dengan range 6 . Sedangkan data tes awal pada kelompok kontrol dengan jumlah sampel 12 orang memiliki nilai rata-rata 30.17, standart deviasi 1.749. Nilai minimum 27 dan nilai maksimum 33 dengan range 6. Sedangkan data tes akhir dengan jumlah sampel 12 orang memiliki nilai rata-rata 30.92, standart deviasi 1.7300 . Nilai minimum 29 dan nilai maksimum 35 dengan range 6.

Penelitian terdapat pengaruh pada kelompok eksperimen karena memberikan angka rata-rata (Mean) tes awal 30.75 dan hasil tes akhir 38.83, dengan demikian terjadi peningkatan sebesar 8.08. sedangkan pada kelompok kontrol rata-rata (Mean) tes awal 30.17 dan hasil tes akhir 30.92, dengan demikian terjadi peningkatan sebesar 0.75. dengan demikian latihan footwork yang kelompok eksperimen dapat dijadikan acuan dalam peningkatan kemampuan pukulan dropshot dalam permainan bulutangkis pada mahasiswa PJKR Unismuh Luwuk Banggai.

\section{Daftar Rujukan}

Alhusin, Syahri. 2007. Gemar Bermain Bulutangkis. CV Seti-Aji. Surakarta.

Ali Maksum. 2012. Metodologi Penelitian Dalam Olahraga. Surabaya: Unesa University Press.

Ardiansyah Nur, dkk. 2020. Pengaruh Latihan Pull Over dan Squat Jump Terhadap Kemampuan Smash Bulutangkis. Jurnal Pendidikan Olahraga 10 (1) : 1-7

Arikunto, Suharsimi. 2004. Prosedur Penelitian (Suatu Pendekatan Praktik). Jakarta: Rineka Cipta.

2010 . Prosedur Penelitian (Suatu Pendekatan Praktik). Jakarta: Rineka Cipta.

Awan, Hariono. 2006. Metode Melatih Fisik Pencak Silat. Yogyakarta: Fakultas Ilmu Keolahragaan Universitas Negeri Yogyakarta.

Djoko Pekik Irianto. 2002. Dasar Kepelatihan. Yogyakarta: FIK UNY 
Journal PANRITA: Journal of Education, Research and Technology

Homepage: https://journal.umpalopo.ac.id/index.php/panrita

Email: mailto:panrita.fkipumpalopo@gmail.com

Harsono. 1988. Coaching dan Aspek-Aspek Psikologis Dalam Coaching. Jakarta: Debdikbud Dirjen Dirti PPLPTK.

Muhajir. 2004. Pendidikan Jasmani Teori dan Praktek. Jakarta: PT Erlangga.

Sapta Kunta Purnama. 2010. Kepelatihan Bulutangkis Modern. Surakarta: Yuma Pustaka

Subardjah, Herman. 2000. Bulutangkis. Bandung: Pioner Jaya.

Sugiyono. 2010. Metode Penelitian Pendidikan Pendekatan Kuantitatif, kualitatif, dan $R \& D$. Bandung: Alfabeta.

Sukadiyanto. 2005. Teori dan Metode Melatih Fisik Petenis. Yogyakarta: FIK UNY.

Surisman. 2010. Pengaruh Circuit Training dan Interval Training Terhadap Hasil Vo2Max Siswa Ekstrakurukuler Bolabasket. Jurnal Penjaskesrek. 4 (2). 20-27

Tanjung, Husni Wardi. 2005. Bermain Melalui Gerak dan Lagu di Taman Kanak-Kanak. Jakarta: Departemen Pendidikan Nasional.

Suharno, HP. 1993. Ilmu Kepelatihan Olahraga. Bandung. PT. Karya Ilmu. 